\title{
2017 Clinical practice guidelines for dyslipidemia of Korean children and adolescents
}

Jung Sub Lim, MD, PhD ${ }^{1}$, Eun Young Kim, MD, PhD², Jae Hyun Kim, MD, PhD ${ }^{3}$, Jae-Ho Yoo, MD, PhD ${ }^{4}$, Kyung Hee Yi, MD, PhD , Hyun Wook Chae, MD, PhD ${ }^{6}$, Jin-Ho Choi, MD, PhD ${ }^{7}$, Ji Young Kim, RD, CED, PhD ${ }^{8}$, II Tae Hwang, MD, PhD ; and the Committee of Dyslipidemia of Korean Children and Adolescents on behalf of Korean Society of Pediatric Endocrinology (KSPE)

${ }^{1}$ Department of Pediatrics, Korea Cancer Center Hospital, Seoul, Korea; ${ }^{2}$ Department of Pediatrics, Chosun University School of Medicine, Kwangju, Korea; ${ }^{3}$ Department of Pediatrics, Seoul National University Bundang Hospital, Seongnam, Korea; ${ }^{2}$ Department of Pediatrics, Dong-A University College of Medicine, Busan, Korea; ${ }^{5}$ Department of Pediatrics, Wonkwang University, Sanbon Medical Center, Sanbon, Korea; ${ }^{6}$ Department of Pediatrics, Gangnam Severance Hospital, Yonsei University College of Medicine, Seoul, Korea; ${ }^{7}$ Department of Pediatrics, Asan Medical Center, University of Ulsan College of Medicine, Seoul, Korea; ${ }^{8}$ Department of Food Service and Nutrition Care, Seoul National University Hospital, Seoul, Korea; ${ }^{9}$ Department of Pediatrics, Kangdong Sacred Heart Hospital, Hallym University College of Medicine, Seoul, Korea

The Committee on Dyslipidemia of Korean Pediatric and Adolescents of the Korean Society of Pediatric Endocrinology has newly developed evidence-based clinical practice guidelines for dyslipidemia in Korean children and adolescents. These guidelines were formulated with the Grading of Recommendations, which include both the strength of recommendations and the quality of evidence. In the absence of sufficient evidence, conclusions were based on expert opinion. These guidelines are based on the 2011 National Heart, Lung, and Blood Institute Guidelines, which focus on the prevention of cardiovascular disease in children and draw from a comprehensive review of evidence. These guidelines contain the definition of and screening process for dyslipidemia and in troduce new dietary methods: the Cardiovascular Health Integrated Lifestyle Diet (CHILD)-1, the CHILD-2-low-density lipoprotein cholesterol, and the CHILD-2-triglyceride. Potential drug therapies for dyslipidemia along with their main effects and doses were also included.

Key words: Practice guidelines, Dyslipidemia, Child, Adolescent, Korea

\section{Key message}

Question: How are children and adolescents with dyslipidemia treated and managed in Korea?

Finding: 2017 guidelines recommend to measure nonfasting non-HDL-C as a screening test and introduce new diet methods: Cardiovascular Health Integrated Lifestyle Diet (CHILD)-1, CHILD-2-low-density lipoprotein cholesterol, and CHILD-2-triglyceride. Statin is the only drug approved in children older than 10 years.
Meaning: New clinical practice guidelines for treating and managing dyslipidemia of Korean children and adolescents are provided.

\section{Introduction}

Cardiovascular disease (CVD) is a major cause of morbidity and mortality worldwide, including in Korea. ${ }^{1,2)}$ The prevalence of CVD in Korea has historically been much lower than the rate reported in Western countries. Recently, however, the CVDassociated mortality rate in Korea has increased to 27.6\%, which is comparable to that in the United States (US). ${ }^{2)}$

Increased total cholesterol (TC), low-density lipoprotein cholesterol (LDL-C), triglyceride (TG), and decreased highdensity lipoprotein cholesterol (HDL-C) are well-known risk factors associated with CVD. ${ }^{3-6)}$ The Korean Heart Study, a 10year prospective study of 430,920 adult men and women, also concluded that high TC and low HDL-C levels increased the risk of CVD.7)

Dyslipidemia is closely related to other CVD risk factors, such as hypertension, obesity, and smoking status, not only in adults but also in children and adolescents. ${ }^{3,8)}$ Furthermore, the prevalence of obesity and metabolic syndrome, which are other risk factors for CVD, has steadily increased in Korea and is now comparable to the rate reported in the US. ${ }^{6,9)}$ This trend likely resulted from recent changes in dietary habits among Korean people that are commonly associated with a western lifestyle. ${ }^{9,10)}$

Although CVD does not usually develop until the fourth decade of life, it is well known that atherosclerosis begins in childhood. ${ }^{8,11,12)}$ The initial stages of atherosclerosis and its progression are associated with dyslipidemia. ${ }^{13)}$ Autopsy data

\footnotetext{
Corresponding author: ॥ Tae Hwang, MD, PhD. Department of Pediatrics, Kangdong Sacred Heart Hospital, Hallym University, College of Medicine, 150 Seongan-ro, Gangdong-gu, Seoul 05355, Korea 
from the Pathobiological Determinants of Atherosclerosis in Youth Study showed a strong correlation between high cholesterol and the development of fatty streaks and fibrous plaques in coronary vasculature at an early age. ${ }^{14)}$ In the Bogalusa Heart Study, the extent of fatty streaks and fibrous plaques increased with age and was correlated with antecedent serum TG, veryhigh LDL-C, and obesity. ${ }^{3)}$

Among Korean children and adolescents aged 10-19 years, $20 \%$ had at least one type of dyslipidemia. ${ }^{15)}$ The prevalence of hypercholesterolemia, high LDL-C, high TG, and low HDL-C concentrations among Korean children and adolescents was $6.5 \%, 4.7 \%, 10.1 \%$, and $11.9 \%$, respectively. ${ }^{16}$ ) The rate of dyslipidemia in Korean obese adolescents has been reported as $56.1 \%{ }^{15)}$

Early recognition of and intervention for dyslipidemia in Korean children and adolescents is important for preventing CVD later in life. In this context, the Committee on Pediatric Dyslipidemia of the Korean Society of Pediatric Endocrinology (KSPE) has recently developed evidence-based clinical practice guidelines to treat dyslipidemia in Korean children and adolescents.

\section{Definition of dyslipidemia}

Several studies, such as the Lipid Research Clinics Prevalence Study and the National Health and Nutrition Examination Survey, have shown that there are sexual, racial, and ethnic differences in lipid profiles and also in the overall prevalence of dyslipidemia. ${ }^{17,18)}$ The mean and 50th percentiles for TC, LDL-C, non-HDL-C, TG, and HDL-C were similar between Koreans and Caucasians from the US. ${ }^{17,18)}$ According to the Korea National Health and Nutrition Examination Survey IV (2007-2009), the 95th percentiles for TC and LDL-C and the 10th percentile for HDL-C in Korean children and adolescents aged $10-18.9$ years were $203 \mathrm{mg} / \mathrm{dL}, 129 \mathrm{mg} / \mathrm{dL}$, and $38 \mathrm{mg} / \mathrm{dL}$, respectively. The 90th and 95th percentiles for TG concentrations were 150 and $185 \mathrm{mg} / \mathrm{dL}$, respectively. In addition, a non-HDL-C of $145 \mathrm{mg} / \mathrm{dL}$

Table1. Definition of dyslipidemia in children and adolescents

\begin{tabular}{lccc}
\hline Variable & Acceptable & Borderline $^{\text {a) }}$ & Abnormal $^{\text {b) }}$ \\
\hline Total cholesterol (mg/dL) & $<170$ & $170-199$ & $\geq 200$ \\
LDL-C (mg/dL) & $<110$ & $110-129$ & $\geq 130$ \\
Non-HDL-C (mg/dL) & $<120$ & $120-144$ & $\geq 145$ \\
Triglyceride (mg/dL) & & & \\
0-9 years & $<75$ & $75-99$ & $\geq 100$ \\
10-19 years & $<90$ & $90-129$ & $\geq 130$ \\
HDL-C (mg/dL) & $>45$ & $40-45$ & $<40$
\end{tabular}

LDL-C, low-density lipoprotein cholesterol; Non-HDL-C, non-high-density lipoprotein cholesterol; HDL-C, high-density lipoprotein.

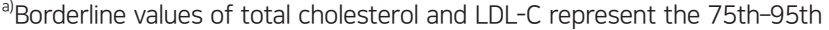
percentile. ${ }^{b}$ Abnormal values of total cholesterol and LDL-C represent the 95th percentile, except for $\mathrm{HDL}-\mathrm{C}$ which represents the 10th percentile. ${ }^{16)}$ Adapted from National Heart, Lung, and Blood Institute 2011. ${ }^{20)}$

Non-HDL-C=TC-HDL-C corresponds to approximately the 90 th to 95 th percentiles. ${ }^{15,19)}$

The Committee of Clinical Practice Guidelines of the KSPE decided to adopt the National Heart Lung and Blood Institute (NHBLI) 2011 guidelines for dyslipidemia to prevent adulthood CVD by lifestyle modification or medical intervention. ${ }^{20)}$ The cutoff levels for serum lipid levels to diagnose dyslipidemia in Korean children and adolescents are listed and defined in Table 1.

There have been controversies in the optimum TG cutoff level. Because carbohydrates make up a major part of the Korean traditional diet, some researchers have insisted that a higher TG concentration of $150 \mathrm{mg} / \mathrm{dL}$, which corresponds to the 90th percentile of Korean adolescents, is more appropriate in defining dyslipidemia. ${ }^{15)}$ However, recent studies have shown that the consumption of simple sugars, fructose, and alcohol is a main factor that increases TG levels. ${ }^{21,22)}$ Furthermore, because TG is the main target of lifestyle modification in dyslipidemia, we decided to define hypertriglyceridemia as a TG concentration > $130 \mathrm{mg} / \mathrm{dL}$. For Korean children younger than 10 years of age, further studies will be required to determine more appropriate reference and cutoff points for dyslipidemia.

According to the cutoff points of the NHBLI guidelines, $19.7 \%$ of Korean children and adolescents from 10-18 years of age had at least one abnormal lipid concentration. ${ }^{15)}$ The prevalence of hypercholesterolemia, high LDL-C, high TG, and low HDL-C $(<40 \mathrm{mg} / \mathrm{dL})$ was $6.5 \%(5.8 \%$ in males, $7.4 \%$ in females), $4.7 \%$ (4.1\% in males, $5.5 \%$ in females), $10.1 \%$ (9.8\% in males, $10.3 \%$ in females), and $11.9 \%$ (14.5\% in males, $9.5 \%$ in females), respectively. ${ }^{15,16)}$ The prevalence of dyslipidemia was $20.7 \%, 39.6 \%$, and $56.1 \%$ for boys (and $24.5 \%, 36.6 \%$, and $53.1 \%$ for girls) who were normal weight, overweight, and obese, respectively. ${ }^{16)}$

\section{Screening recommendations}

Screening for lipids in children is based on the rationale that early identification and control of pediatric dyslipidemia will reduce the risk and severity of CVD in adulthood. Therefore, the Committee of Clinical Practice Guidelines of KSPE recommends "universal screening." Universal screening in this guideline might be performed to detect those with undiagnosed heterozygous familial hypercholesterolemia who would require more intensive treatment, possibly including pharmacological therapy. ${ }^{20,23)} \mathrm{In}$ contrast, targeted screening based on family history of CVD or hypercholesterolemia fails to detect a substantial number (from $30 \%-60 \%$ ) of children with elevated lipid levels. ${ }^{24}$ Almost 51\% of untreated children with dyslipidemia will go on to develop clinical CVD by 50 years of age, and 5\% do so by 30 years of age..$^{25)}$

Universal lipid screening should be performed with the measurement of nonfasting non-HDL-C in all children aged 9-11 and 17-21 years. Non-HDL-C is calculated as follows: nonHDL-C =TC-HDL-C. Non-HDL-C includes all cholesterol types present in lipoprotein particles (LDL-C, lipoprotein(a), 
intermediate density lipoprotein, and very-low-density lipoprotein) that are considered atherogenic. Therefore, non-HDL-C is a better independent predictor of CVD than LDL-C and is also as good a predictor of future adulthood dyslipidemia that can replace LDL-C. ${ }^{26-28)}$ If non-HDL-C is $>145 \mathrm{mg} / \mathrm{dL}, 2$ additional fasting lipid panels (at least 2 weeks but no more than 12 weeks apart) should be obtained and the average values are used.

Screening for dyslipidemia is not recommended until 2 years of age. For children aged 2-8 and 12-16 years, routine lipid screening is also not recommended. Targeted screening is only encouraged if there is a family history of high cardiovascular risk or other risk factors and conditions. The risk factors and conditions to consider for the screening and treatment decisions in children with dyslipidemia are included in Tables 2 and $3 .^{20)}$

\section{Management}

Rising rates of dyslipidemia in Korean children and adolescents might be due to increases in adoption of the western lifestyle, especially the westernized diet and decrease in physical activity. ${ }^{2930)}$ Therefore, lifestyle modifications, such as promoting a healthy diet and regular physical activity, are thought to be essential in treating dyslipidemia. The algorithm used for dyslipidemia management is shown in Fig 1.

\section{Lifestyle change and diets}

The KSPE guidelines recommend that all children and adolescents engage in moderate-to-vigorous physical activity for at least one hour a day and limit sedentary activity, including television, internet, and video games, to $<2$ hours a day. Cigarette exposure also should be strongly discouraged. In addition, all children and adolescents should try to attain an ideal body weight (body mass index $\leq 85$ th percentile for age and sex).

Any diet change must provide optimal nutrition for growth and development. The 2010 Dietary Guidelines for Americans recommend the Cardiovascular Health Integrated Lifestyle Diet (CHILD-1) be used in children and adolescents 2 years of age or older who are at risk for CVD. ${ }^{31)}$

Exclusively breastfeeding should be done until 6 months of age. If direct breastfeeding is impossible, use a breast pump, and if any breastfeeding is not available, iron-fortified infant formula

Table 2. Risk factors of dyslipidemia

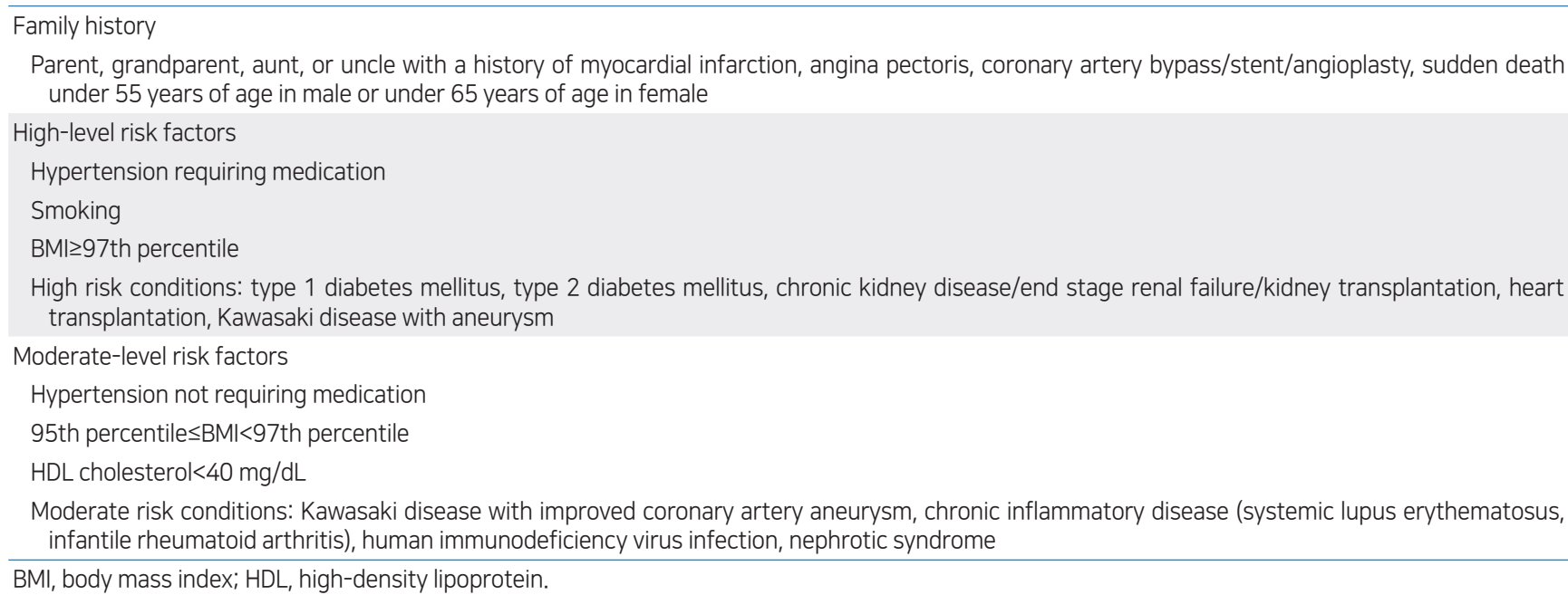

Table 3. Screening for dyslipidemia

\begin{tabular}{|c|c|}
\hline Age & Recommendation \\
\hline Birth-2 yr & No lipid screening \\
\hline \multirow[t]{2}{*}{$2-8$ yr } & No routine lipid screening \\
\hline & Measure fasting lipid profile if child has a family history of dyslipidemia, moderate or high-risk factors and conditiona) \\
\hline \multirow[t]{3}{*}{$9-11 \mathrm{yr}$} & Universal screening \\
\hline & Measure nonfasting non-HDL-C \\
\hline & Fasting lipid testing if non-HDL-C $\geq 145 \mathrm{mg} / \mathrm{dL}^{\mathrm{a}}$ \\
\hline \multirow[t]{2}{*}{$12-16$ yr } & No routine lipid screening \\
\hline & Measure fasting lipid profile if child has a family history of dyslipidemia, moderate or high-risk factors and conditiona) \\
\hline \multirow[t]{3}{*}{$17-21 \mathrm{yr}$} & Universal screening \\
\hline & Measure nonfasting non-HDL-C \\
\hline & Fasting lipid testing if non-HDL-C $\geq 145 \mathrm{mg} / \mathrm{dL}^{\mathrm{a}}$ \\
\hline
\end{tabular}

HDL-C, high-density lipoprotein cholesterol.

a) Two additional fasting lipid tests measured 2 weeks but within 3 months. 


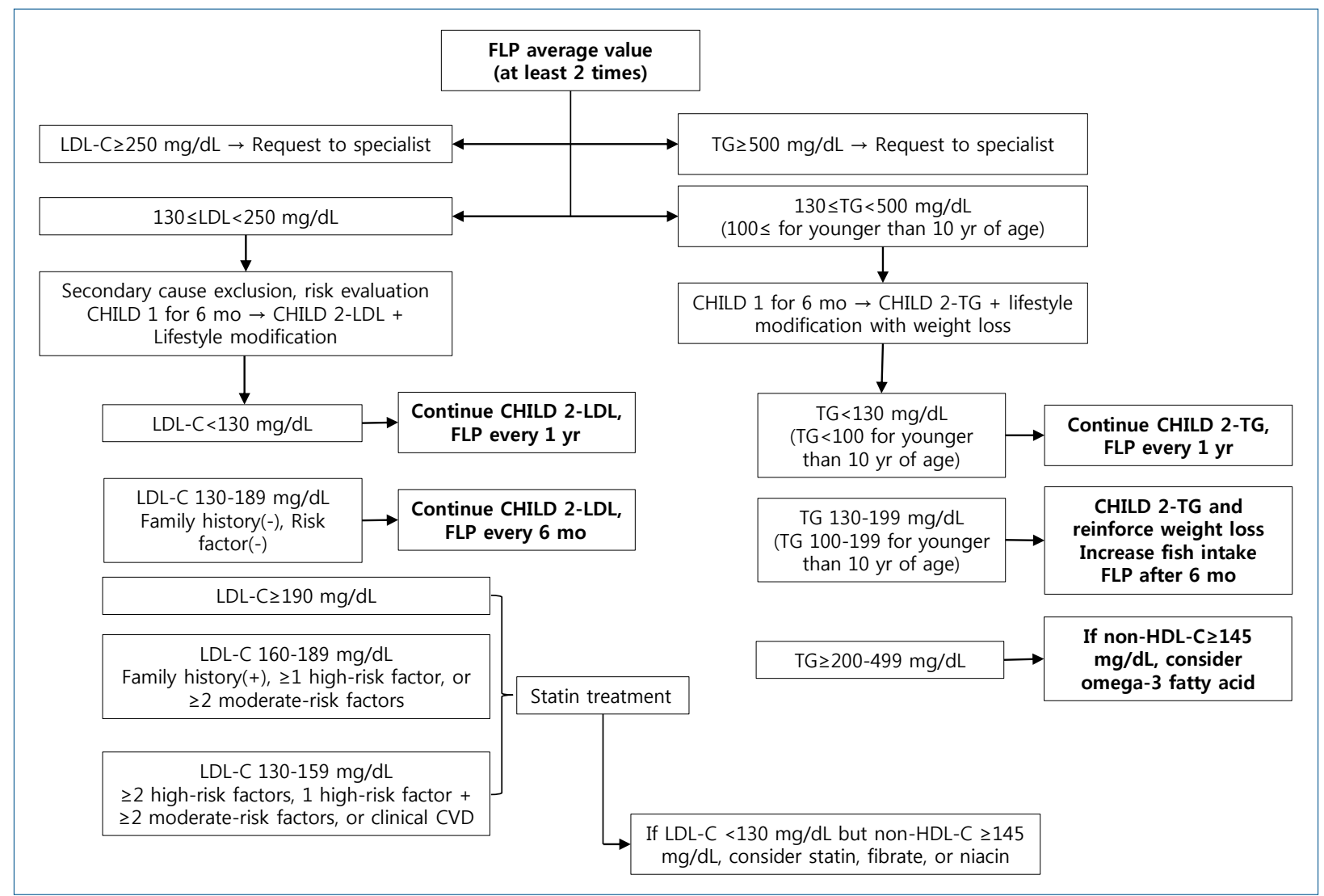

Fig. 1. Algorithm for dyslipidemia treatment. FLP, fasting lipid profile; LDL-C, low-density lipoprotein cholesterol; CHILD 1, Cardiovascular Health Integrated Lifestyle Diet 1; CHILD 2-LDL, Cardiovascular Health Integrated Lifestyle Diet 2; non-HDL-C, non-high-density lipoprotein cholesterol; TG, triglycerides; CVD, cardiovascular disease.

should be fed. Breastfeeding should continue for at least 12 months while gradually adding solids. If breast milk decreases, feed iron-fortified formula until 12 months. Infants under 12 months of age should not limit their fat intake without medical indication and limit $100 \%$ juice to about $120 \mathrm{~mL}$ per day, drink water without any other beverages.

Consult health-care provider about low-fat milk intake after 12 months of age if a family history of obesity, heart disease, or dyslipidemia is present. ${ }^{20)}$

If the fasting lipid profile findings exceed the therapeutic goals after a 3-month trial of the CHILD-1 diet, then the CHILD-2LDL, or CHILD-2-TG diet should be recommended based on specific abnormal lipid parameters.

The detailed contents of each diet are listed in Table 4. The CHILD-1 urges specific protocols: drink fat-free unflavored milk primarily, limit/avoid sugar-sweetened beverages, encourage water consumption, limited total fat content $(25 \%-30 \%$ of the daily $\mathrm{kcal} /$ estimated energy requirements [EER] per day for age/ gender), limit saturated fat $8 \%-10 \%$ of the daily kcal/EER, avoid transfat as much as possible, and recommend monounsaturated and polyunsaturated fat up to $20 \%$ of the daily $\mathrm{kcal} / \mathrm{EER}$, and limit cholesterol intake to $<300 \mathrm{mg} /$ day. $^{20)}$ In addition, these recommendations advocate the intake of dietary fiber $(14 \mathrm{~g} / 1,000$ $\mathrm{kcal}$ ), limiting naturally sweetened juice (no added sugar) to 120 $\mathrm{mL} /$ day, limiting sodium intake, and encouraging healthy eating habits overall. The CHILD-2 is divided into CHILD-2-LDL and CHILD-2-TG guidelines depending on the dyslipidemia target. Above all, it is important to refer these children and adolescents to a registered dietitian for family-based medical nutrition therapy and to decrease their total sugar intake. The CHILD-2 diet recommends the following: avoiding transfats, consuming $<200$ $\mathrm{mg}$ /day of cholesterol, and sustaining total, saturated, and monounsaturated fat at $25 \%-30 \%, 7 \%$, and $<10 \%$ of total calories, respectively. Supportive dietary plans are different between the CHILD-2-LDL and the CHILD-2-TG. The CHILD-2-LDL diet recommends phytosterols up to $2 \mathrm{~g}$ per day as substitutes for dietary fats in children with familial hypercholesterolemia who are older than 2 years. Water-soluble fiber, such as psyllium, can be added to a low-fat, low-saturated fatty acid diet (6 g/day for children from 2-12 years and $12 \mathrm{~g}$ /day for children $>12$ years). With the CHILD-2-TG, an increase in fish intake is critical in improving the levels of omega-3 fatty acids. TG levels are very responsive to weight loss, diet composition, and exercise. ${ }^{32}$

\section{Drug therapy}

Decisions regarding the need for drug therapy should be based on the average values from at least 2 fasting lipid tests obtained at least 2 weeks but no more than 3 months apart.

Drug therapy is recommended in children $\geq 10$ years with a poor response to diet and lifestyle therapy for at least 6-12 

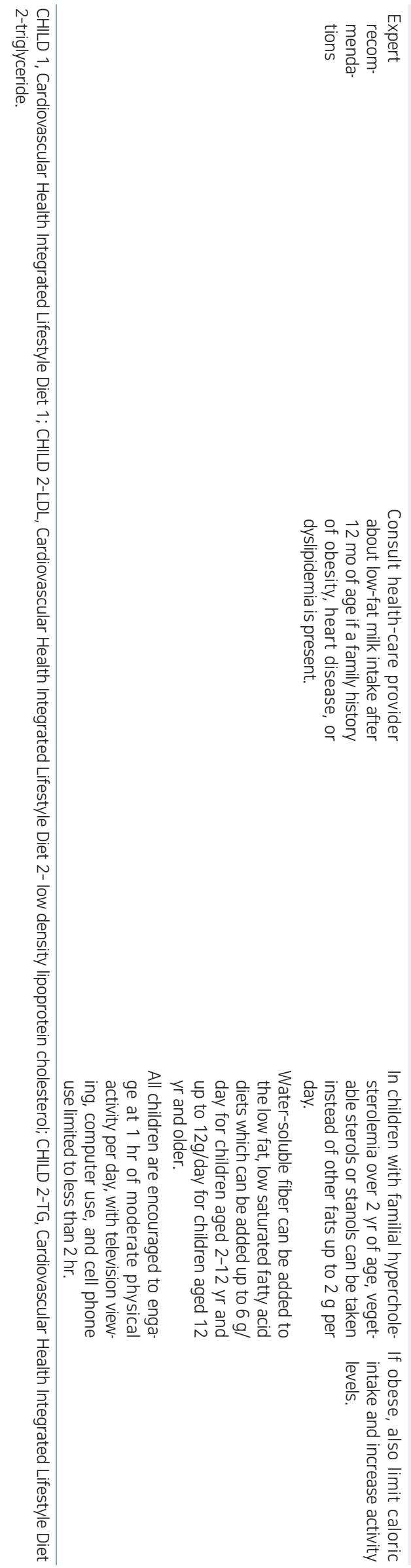

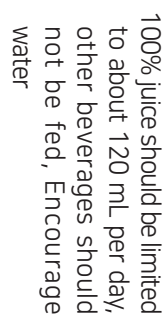
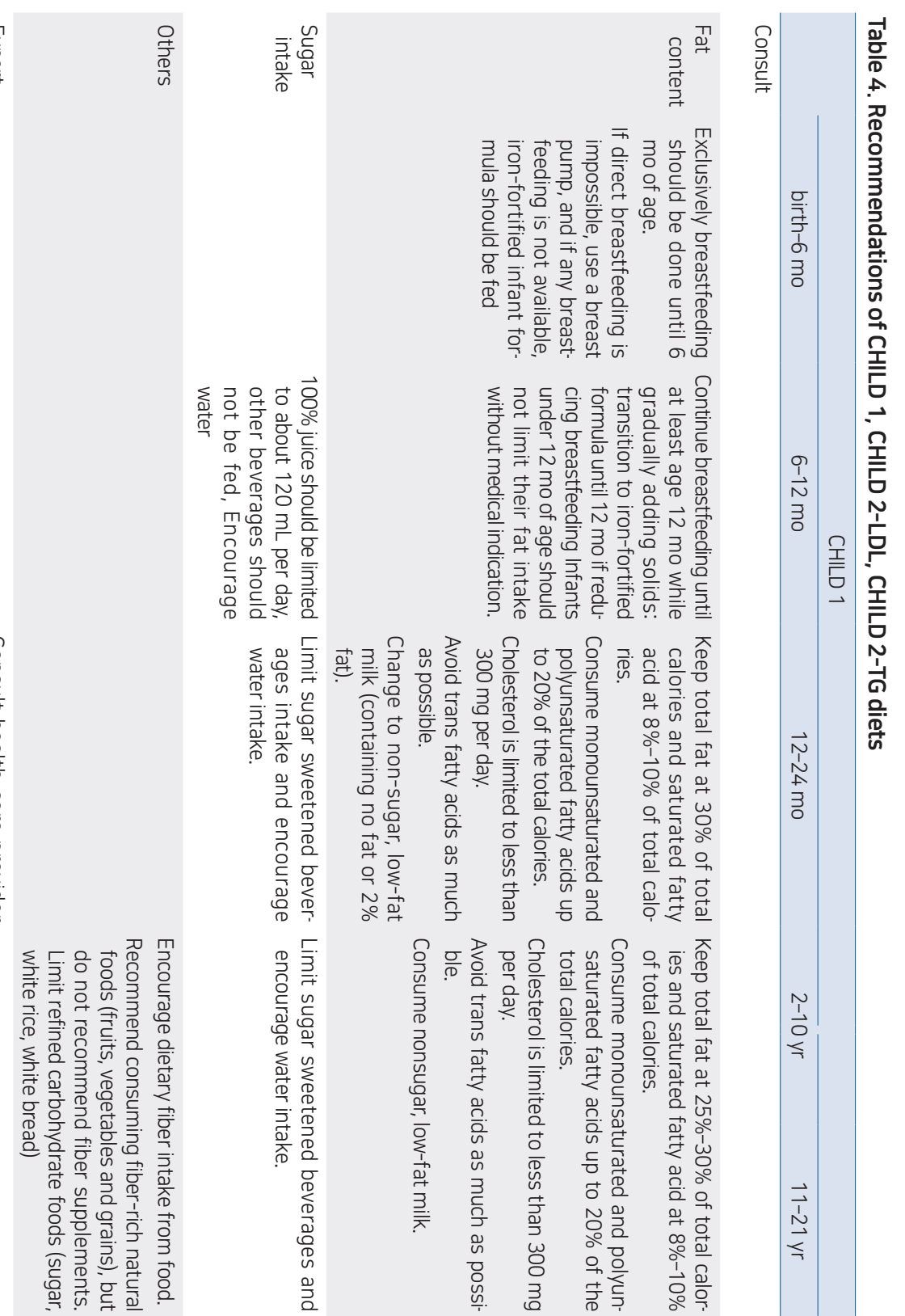

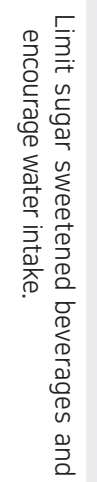

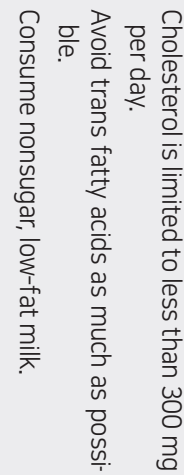

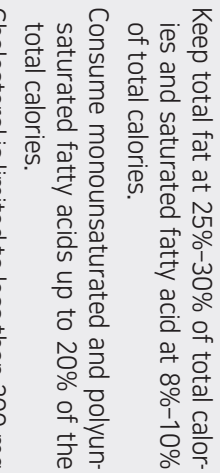

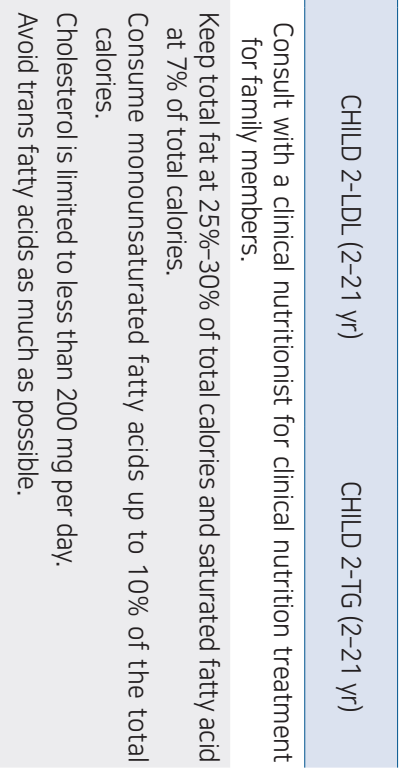


months. ${ }^{20)}$ The choice of medication depends on the lipid profile, age, sex, family history, and the pediatricians' experience. ${ }^{33)}$ In Korea, at least $0.41 \%$ of Korean children and adolescents are candidates for pharmacological treatment. ${ }^{16)}$

Children with average LDL-C levels $\geq 250 \mathrm{mg} / \mathrm{dL}$ or TG $\geq$ $500 \mathrm{mg} / \mathrm{dL}$ should be referred directly to a lipid specialist. If the TG concentration is $>500 \mathrm{mg} / \mathrm{dL}$, there is a risk of pancreatitis, and specialist consultation is therefore necessary. ${ }^{34)}$

Statin treatment is generally not started in children under the age of 10 , and it is limited to patients homozygous for familial hypercholesterolemia or with LDL-C $\geq 400 \mathrm{mg} / \mathrm{dL}$, primary hypertriglyceridemia $\geq 500 \mathrm{mg} / \mathrm{dL}, \mathrm{CVD}$, or cardiac transplantation.

If the LDL-C remains $\geq 190 \mathrm{mg} / \mathrm{dL}$ after a 6-month trial of lifestyle management (CHILD-1 $\rightarrow$ CHILD-2-LDL) for children aged 10 years and older, statin therapy should be considered. ${ }^{20,35)}$ For patients with an LDL-C concentration between 160-189 $\mathrm{mg} / \mathrm{dL}$, statin treatment should be considered if there is a positive family history of premature CVD in first-degree relatives, at least one high-level risk factor or risk condition, or at least 2 moderatelevel risk factors or risk conditions. If the LDL-C concentration is between 130-159 after 6 months of lifestyle modification, and if the children have at least 2 high-risk factors or conditions or at least one high-level risk factor and two or more moderate-risk factors or conditions or clinical CVD, statin therapy should be considered.

In children who are at least 10 years of age, the administration of statins, fibrates, or niacin may be considered if the LDL-C has reached its target but the non-HDL-C remains $\geq 145 \mathrm{mg} / \mathrm{dL} .{ }^{20,36}$ )

When TG improves with weight control and lifestyle changes in children with hypertriglyceridemia, medication therapy is unnecessary. As a supportive medical therapy, the use of omega-3 fatty acids is suggested along with lifestyle modification via the CHILD-2-TG, especially in children with hypertriglyceridemia. When the affected child has TG levels from $200-499 \mathrm{mg} / \mathrm{dL}$ and a non-HDL-C result $\geq 145 \mathrm{mg} / \mathrm{dL}$, omega-3 fatty acid treatment may be considered. ${ }^{36}$
However, safety issues remain unclear due to the limited experience with omega-3 fatty acids in children, which have only been used in a small number of cases. ${ }^{37)}$ (Table 5)

Statins and bile acid-binding resins are the two main classes of medications currently used to treat this condition in pediatric patients. Commonly used medications are listed in Table 6 . Statins that are approved by the U.S. Food and Drug Administration (FDA) in children older than 10 years include pravastatin, simvastatin, lovastatin, and atorvastatin. Cholesterol-absorption inhibitors, such as niacin and fibrates, are not yet approved by the US FDA.

A statin is recommended as the initial medication of choice for children with elevated LDL-C or non-HDL-C levels. Statins inhibit the rate-limiting enzyme $\beta$-hydroxy $\beta$-methylglutarylCoA reductase and induce endogenous synthesis of cholesterol. Statins are effective at lowering cholesterol levels by $20 \%-50 \%$ below the baseline. They are also known to have minimal side effects and do not affect growth. ${ }^{31,38,39)}$ The treatment regime should begin at the lowest dose given once daily at bedtime. Atorvastatin can be taken either in the morning or evening because of its long half-life. Before beginning statin treatment, baseline measurements of alanine aminotransferase, aspartate aminotransferase, and creatinine kinase should be obtained. Liver function tests, creatinine kinase, and a fasting lipid profile should be repeated at 4 and 8 weeks after the initiation of therapy and then again every 3 to 6 months. If liver enzymes are more than 3 times the upper limit or the creatinine kinase is $>10$ times the upper limit of the reference range, the statin medication should be stopped. ${ }^{40,41)}$

The target LDL-C value is typically $<130 \mathrm{mg} / \mathrm{dL}$, but if the patient is at high risk, such as with familial hypercholesterolemia or diabetes mellitus, the target LDL-C level should be maintained below $100 \mathrm{mg} / \mathrm{dL}$. If target levels are not achieved within three months, the statin dose can be gradually increased to the maximum amount.

Since statins are potentially teratogenic, it is essential for physicians to confirm that adolescent girls are not pregnant before

\section{Table 5. Recommendations for pharmacological treatment of dyslipidemia}

\begin{tabular}{|c|c|}
\hline Age & Treatment \\
\hline Birth-9 yr & $\begin{array}{l}\text { Pharmacological treatment is limited to children with homozygote familial hypercholesterolemia, } \mathrm{LDL}-\mathrm{C} \geq 400 \mathrm{mg} / \mathrm{dL} \text {, primary } \\
\text { hypertriglyceridemia ( } \mathrm{TG} \geq 500 \mathrm{mg} / \mathrm{dL} \text { ), cardiovascular disease, and cardiac transplantation. }\end{array}$ \\
\hline \multirow[t]{10}{*}{$10-21$ yr } & Refer to lipid specialist \\
\hline & LDL-C $\geq 250 \mathrm{mg} / \mathrm{dL}$ or $\mathrm{TG} \geq 500 \mathrm{mg} / \mathrm{dL}$ \\
\hline & Statin treatment \\
\hline & 1) $\mathrm{LDL}-\mathrm{C} \geq 190 \mathrm{mg} / \mathrm{dL}$ \\
\hline & $\begin{array}{l}\text { 2) } \mathrm{LDL}-\mathrm{C} 160-189 \mathrm{mg} / \mathrm{dL} \text {, and a positive family history of premature CVD in first-degree relatives or at least one high-level risk factor } \\
\text { or risk condition or at least } 2 \text { moderate-level risk factors or risk conditions }\end{array}$ \\
\hline & $\begin{array}{l}\text { 3) } \mathrm{LDL}-\mathrm{C} \geq 130-159 \mathrm{mg} / \mathrm{dL} \text {, and at least } 2 \text { high-level risk factors or conditions or at least } 1 \text { high-level risk factor and } 2 \text { moderate-level } \\
\text { risk factors or conditions }\end{array}$ \\
\hline & Omega-3 fish oil \\
\hline & TG $\geq 200-499$ mg/dL, non-HDL-C $\geq 145$ mg/dL \\
\hline & Statin, fibrates, or niacin may be considered \\
\hline & If non-HDL-C $\geq 145 \mathrm{mg} / \mathrm{dL}$ after LDL-C has reached the target level \\
\hline
\end{tabular}

LDL-C, low-density lipoprotein cholesterol; TG, triglyceride; HDL-C, high-density lipoprotein cholesterol. 
Table 6. Major effects and dose of medications for dyslipidemia

\begin{tabular}{|c|c|c|c|c|c|}
\hline Type of medication & Major effects & Adverse effects & Common names & Daily dose & $\begin{array}{l}\text { FDA approval } \\
\text { in children }\end{array}$ \\
\hline $\begin{array}{l}\text { HMG-CoA reductase } \\
\text { inhibitors }\end{array}$ & $\begin{array}{l}\downarrow \text { LDL cholesterol \&TG, } \\
\uparrow \mathrm{HDL} \text { cholesterol }\end{array}$ & $\begin{array}{l}\uparrow \text { Liver transaminases } \uparrow \text { Creatine } \\
\text { kinase, myopathy, rhabdomyolysis }\end{array}$ & $\begin{array}{l}\text { Lovastatin (Mevacor) } \\
\text { Simvastatin (Zocor) } \\
\text { Pravastatin (Pravachol) } \\
\text { Atorvastatin (Lipitor) }\end{array}$ & $\begin{array}{r}20-80 \mathrm{mg} \\
20-80 \mathrm{mg} \\
20-80 \mathrm{mg} \\
5-80 \mathrm{mg}\end{array}$ & $\begin{array}{l}\text { Approved } \\
\text { Approved } \\
\text { Approved } \\
\text { Approved }\end{array}$ \\
\hline $\begin{array}{l}\text { Cholesterol absorption } \\
\text { inhibitors }\end{array}$ & $\downarrow$ LDL cholesterol & Myopathy, gastrointestinal upset & Ezetimibe & $10 \mathrm{mg}$ & Not approved \\
\hline Fibric acid derivatives & $\downarrow \mathrm{TG}, \uparrow \mathrm{HDL}$ cholesterol & $\begin{array}{l}\text { Dyspepsia, constipation, myositis, } \\
\text { anemia }\end{array}$ & $\begin{array}{l}\text { Gemfibrozil } \\
\text { Fenofibrate } \\
\text { Clofibrate }\end{array}$ & $\begin{array}{c}1,200 \mathrm{mg} \\
48-145 \mathrm{mg} \\
2 \mathrm{~g}^{*}\end{array}$ & $\begin{array}{l}\text { Not approved } \\
\text { Not approved } \\
\text { Not approved }\end{array}$ \\
\hline Omega-3-fish oil & $\downarrow T G$ & & Docosahexaenoic acid (DHA) & 2-4 g (adults) & Not approved \\
\hline $\begin{array}{l}\text { Nicotinic acid (extend- } \\
\text { ed release) }\end{array}$ & $\downarrow$ TG \& LDL cholesterol & Flushing, hepatic toxicity & & $\begin{array}{c}1,000-2,250 \\
\mathrm{mg}^{*}\end{array}$ & \\
\hline Bile acid sequestrants & $\downarrow$ LDL cholesterol, $\uparrow$ TG & $\begin{array}{l}\text { Limited to gastrointestinal tract; } \\
\text { gas, bloating, constipation, cramps }\end{array}$ & $\begin{array}{l}\text { Cholestyramine } \\
\text { Colestipol } \\
\text { Colesevelam }\end{array}$ & $\begin{array}{c}8-16 \mathrm{~g} \# 2 \\
2.5-20 \mathrm{~g} \\
1.25-4.375 \mathrm{~g}\end{array}$ & $\begin{array}{l}* * \\
* * \\
* *\end{array}$ \\
\hline
\end{tabular}

FDA, Food and Drug Administration; HMG-CoA, 3-hydroxy-3-methylglutaryl coenzyme A; LDL, low-density lipoprotein; TG, triglyceride; HDL, high-density lipoprotein.

*Lack of evidence-based research on dose in children. ${ }^{* *}$ Although used in clinical practice, there is a lack of evidence-based research in children.

initiating statin therapy.

Bile acid sequestrants are the first line of therapy for children with dyslipidemia as these compounds are not absorbed systemically. ${ }^{42)}$ They work by preventing cholesterol reuptake in the enterohepatic circulation. However, cholestyramine and colestipol are unpalatable and are associated with gastrointestinal side effects, including bloating, nausea, diarrhea, and constipation. Therefore, compliance with this type of therapy is generally poor.

Ezetimibe (a cholesterol-absorption inhibitor) enters the enterohepatic circulation and reduces bile acid reuptake as well as cholesterol absorption. Ezetimibe is approved in children older than 10 years of age at a dosage of $10 \mathrm{mg} /$ day as an adjuvant to statin therapy. In adults, ezetimibe has been shown to reduce the LDL-C by $20 \%{ }^{43)}$ No studies have investigated the treatment of ezetimibe alone in children, but data regarding children's experience with niacin and fibrates are also limited.

Therefore, niacin, fibrates, and ezetimibe should only be initiated after consulting with a lipid specialist. When these drugs are used in combination in children, they exert an increased combined effect, but the occurrence of side effects is not increased.

\section{Conclusions}

Atherosclerosis begins in childhood and can lead to CVD in adulthood. Early detection and proper management of dyslipidemia in children and adolescents are urgently needed to reduce adult CV morbidity. The 2017 Clinical Practice Guidelines for Dyslipidemia of Korean Children and Adolescents are intended to help identify children who are at increased risk of CVD and may benefit from the early screening and intervention of dyslipidemia. These guidelines provide a schematic approach that will help pediatricians make timely decisions regarding the screening and management of Korean children and adolescents with risks and conditions associated with accelerated atherosclerosis.

\section{Conflicts of interest}

No potential conflict of interest relevant to this article was reported.

\section{Acknowledgments}

The authors greatly appreciate the members of Committee on Dyslipidemia of Korean Pediatric and Adolescents and the Korean Society for Pediatric Endocrinology for their support in developing and publishing these guidelines. This guideline is being simultaneously published in Annals of Pediatric Endo. crinology \& Metabolism and Clinical and Experimental Pe. diatrics.

\section{References}

1. The Global Burden of Disease 2004 Update [Internet]. Geneva (Switzerland): World Health Organization; 2008 [cited 2020 May 3]. Available from: https://www.who.int/healthinfo/global burden disease/ GBD_report_2004update_full.pdf.

2. Korea National Statistical Office. Annual report on the cause of death statistics, 2010 [Internet]. Daejeon (Korea): Statistics Korea; [cited 2020 May 3]. Available from: http://kostat.go.kr/portal/english/news/1/8/ index.board? bmode $=$ read \&bSeq $=\& a S e q=250427 \&$ pageNo $=1 \&$ ro $\mathrm{wNum}=10 \&$ navCount $=10 \&$ currPg $=\&$ sTarget $=$ title.

3. Berenson GS, Srinivasan SR, Bao W, Newman WP 3rd, Tracy RE, Wattigney WA. Association between multiple cardiovascular risk factors and atherosclerosis in children and young adults. The Bogalusa Heart Study. NEngl J Med 1998;338:1650-6.

4. Stamler J, Daviglus ML, Garside DB, Dyer AR, Greenland P, Neaton JD. Relationship of baseline serum cholesterol levels in 3 large cohorts of younger men to long-term coronary, cardiovascular, and all-cause mortality and to longevity. JAMA 2000;284:311-8.

5. Sone H, Tanaka S, Tanaka S, Iimuro S, Oida K, Yamasaki Y, et al. Serum level of triglycerides is a potent risk factor comparable to LDL cholesterol for coronary heart disease in Japanese patients with type 2 diabetes: 
subanalysis of the Japan Diabetes Complications Study (JDCS). J Clin Endocrinol Metab 2011;96:3448-56.

6. Goldbourt U, Yaari S, Medalie JH. Isolated low HDL cholesterol as a risk factor for coronary heart disease mortality. A 21-year follow-up of 8000 men. Arterioscler Thromb Vasc Biol 1997;17:107-13.

7. Jee SH, Jang Y, Oh DJ, Oh BH, Lee SH, Park SW, et al. A coronary heart disease prediction model: the Korean Heart Study. BMJ Open 2014;4:e005025.

8. McGill HC Jr, McMahan CA, Zieske AW, Tracy RE, Malcom GT, Strong JP. Effects of nonlipid risk factors on atherosclerosis in youth with a favorable lipoprotein profile. Circulation 2001;103:1546-50.

9. Ko M, Kim MT, Nam JJ. Assessing risk factors of coronary heart disease and its risk prediction among Korean adults: the 2001 Korea National Health and Nutrition Examination Survey. Int J Cardiol 2006;110:18490

10. Kim S, Moon S, Popkin BM. The nutrition transition in South Korea. Am J Clin Nutr 2000;71:44-53.

11. Lauer RM, Lee J, Clarke WR. Factors affecting the relationship between childhood and adult cholesterol levels: the Muscatine Study. Pediatrics 1988;82:309-18.

12. Kavey RE, Daniels SR, Lauer RM, Atkins DL, Hayman LL, Taubert K, et al. American Heart Association guidelines for primary prevention of atherosclerotic cardiovascular disease beginning in childhood. Circulation 2003;107:1562-6.

13. Raitakari OT, Juonala M, Kahonen M, Taittonen L, Laitinen T, MakiTorkko N, et al. Cardiovascular risk factors in childhood and carotid artery intima-media thickness in adulthood: the Cardiovascular Risk in Young Finns Study. JAMA 2003;290: 2277-83

14. McGill HC Jr, McMahan CA, Malcom GT, Oalmann MC, Strong JP. Effects of serum lipoproteins and smoking on atherosclerosis in young men and women. The PDAY Research Group. Pathobiological Determinants of Atherosclerosis in Youth. Atheroscler Thromb Vasc Biol 1997; 17:95-106

15. Kim SH, Ahn BC, Joung H, Park MJ. Lipid profiles and prevalence of dyslipidemia in Korean adolescents. Endocrinol Metab 2012;27:208-16.

16. Yang S, Hwang JS, Park HK, Lee HS, Kim HS, Kim EY, et al. Serum lipid concentrations, prevalence of dyslipidemia, and percentage eligible for pharmacological treatment of Korean children and adolescents; data from the Korea National Health and Nutrition Examination Survey IV (2007-2009). PLoS One 2012;7:e49253.

17. Hickman TB, Briefel RR, Carroll MD, Rifkind BM, Cleeman JI, Maurer KR, et al. Distributions and trends of serum lipid levels among United States children and adolescents ages 4-19 years: data from the Third National Health and Nutrition Examination Survey. Prev Med 1998;27:879-90.

18. Ford ES, Li C, Zhao G, Mokdad AH. Concentrations of low-density lipoprotein cholesterol and total cholesterol among children and adolescents in the United States. Circulation 2009;119:1108-15.

19. Shim YS, Baek JW, Kang MJ, Oh YJ, Yang S, Hwang IT. Reference values for the triglyceride to high-density lipoprotein cholesterol ratio and nonhigh-density lipoprotein cholesterol in Korean Children and Adolescents: the Korean National Health and Nutrition Examination Surveys 20072013. J Atheroscler Thromb 2016;23:1334-44.

20. Expert Panel on Integrated Guidelines for Cardiovascular Health and Risk Reduction in Children and Adolescents; National Heart, Lung, and Blood Institute. Expert panel on integrated guidelines for cardiovascular health and risk reduction in children and adolescents: summary report. Pediatrics 2011;128(Suppl 5):S213-56.

21. Havel PJ. Dietary fructose: implications for dysregulation of energy homeostasis and lipid/carbohydrate metabolism. Nutr Rev 2005;63:13357

22. Lichtenstein AH, Appel LJ, Brands M, Carnethon M, Daniels S, Franch HA, et al. Summary of American Heart Association Diet and Lifestyle Recommendation revision 2006. Arterioscler Thromb Vasc Biol 2006; 26:2186-91

23. US Preventive Services Task Force. Screening for lipid disorders in children: US Preventive Services Task Force recommendation statement.
Pediatrics 2007;120:e215-9.

24. Haney EM, Huffman LH, Bougatsos C, Freeman M, Fu R, Steiner RD, et al. Screening for lipid disorders in children and adolescents [Internet]. Rockville: Agency for Healthcare Research and Quality; 2007 [cited 2020 May 3]. Available from: http://www.ncbi.nlm.nih.gov/books/ NBK33480/.

25. Slack J. Risks of ischaemic heart-disease in familial hyperlipoproteinaemic states. Lancet 1969;2:1380-2.

26. Srinivasan SR, Frontini MG, Xu J, Berenson GS. Utility of childhood non-high-density lipoprotein cholesterol levels in predicting adult dyslipidemia and other cardiovascular risks: the Bogalusa Heart Study. Pediatrics 2006;118:201-6.

27. Cui Y, Blumenthal RS, Flaws JA, Whiteman MK, Langenberg P, Bachorik PS, Bush TL. Non-high-density lipoprotein cholesterol level as a predictor of cardiovascular disease mortality. Arch Intern Med 2001;161:1413-9.

28. Frontini MG, Srinivasan SR, Xu JH, Tang R, Bond MG, Berenson G. Utility of non-high-density lipoprotein cholesterol versus other lipoprotein measures in detecting subclinical atherosclerosis in young adults (The Bogalusa Heart Study). Am J Cardiol 2007;100:64-8.

29. Hong HR, Kim SU, Kang HS. Physical activity and metabolic syndrome in Korean children. Int J Sports Med 2009;30:677-83.

30. Shin KO, Oh SY, Park HS. Empirically derived major dietary patterns and their associations with overweight in Korean preschool children. Br J Nutr 2007;98:416-21.

31. US department of agriculture; US Department of Health and Human Services. Dietary Guidelines for Americans, 2010. 7th ed. Washington, DC: US Government Printing Office, 2011.

32. Becque MD, Katch VL, Rocchini AP, Marks CR, Moorehead C. Coronary risk incidence of obese adolescents: reduction by exercise plus diet intervention. Pediatrics 1988;81:605-12.

33. McCrindle BW; American Heart Association Writing Group, Urbina EM, Dennison BA, Jacobson MS, Steinberger J, et al. Summary of the American Heart Association's scientific statement on drug therapy of high-risk lipid abnormalities in children and adolescents. Arterioscler Thromb Vasc Biol 2007; 27:982-5.

34. McCrindle BW, Urbina EM, Dennison BA, Jacobson MS, Steinberger J, Rocchini AP, et al. Drug therapy of high-risk lipid abnormalities in children and adolescents: a scientific statement from the American Heart Association Atherosclerosis, Hypertension, and Obesity in Youth Committee, Council of Cardiovascular Disease in the Young, with the Council on Cardiovascular Nursing. Circulation 2007;115:1948-67.

35. Daniels SR. Pediatric guidelines for dyslipidemia. J Clin Lipidol 2015;9(5 Suppl):S5-10.

36. Manlhiot C, Larsson P, Gurofsky RC, Smith RW, Fillingham C, Clarizia NA, et al. Spectrum and management of hypertriglyceridemia among children in clinical practice. Pediatrics 2009;123:458-65.

37. Berglund L, Brunzell JD, Goldberg AC, Goldberg IJ, Sacks F, Murad $\mathrm{MH}$, et al. Evaluation and treatment of hypertriglyceridemia: an Endocrine Society clinical practice guideline. J Clin Endocrinol Metab 2012; 97:2969-89.

38. Wiegman A, Hutten BA, de Groot E, Rodenburg J, Bakker HD, Buller HR, et al. Efficacy and safety of statin therapy in children with familial hypercholesterolemia: a randomized controlled trial. JAMA 2004;292: 331-7.

39. McCrindle BW, Ose L, Marais AD. Efficacy and safety of atorvastatin in children and adolescents with familial hypercholesterolemia or severe hyperlipidemia: a multicenter, randomized, placebo-controlled trial. J Pediatr 2003;143:74-80.

40. de Jongh S, Ose L, Szamosi T, Gagne C, Lambert M, Scott R, et al. Efficacy and safety of statin therapy in children with familial hypercholesterolemia: a randomized, double-blind, placebo-controlled trial with simvastatin. Circulation 2002;106:2231-7.

41. Avis HJ, Vissers MN, Stein EA, Wijburg FA, Trip MD, Kastelein JJ, et al. A systematic review and meta-analysis of statin therapy in children with familial hypercholesterolemia. Arterioscler Thromb Vasc Biol 2007;27: 1803-10.

42. Tonstad S, Knudtzon J, Sivertsen M, Refsum H, Ose L. Efficacy and safety 
of cholestyramine therapy in peripubertal and prepubertal children with familial hypercholesterolemia. J Pediatr 1996;129:42-9.

43. Blagden MD, Chipperfield R. Efficacy and safety of ezetimibe coadministered with atorvastatin in untreated patients with primary hypercholesterolaemia and 044106coronary heart disease. Curr Med Res Opin 2007;23:767-75.
How to cite this article: Lim JS, Kim EY, Kim JH, Yoo JH, Yi $\mathrm{KH}$, Chae HW, et al. 2017 Clinical practice guidelines for dyslipidemia of Korean children and adolescents. Clin Exp Pediatr 2020;63:454-462. https://doi.org/10.3345/cep.2020.01340 